\title{
Asthma characteristics in cleaning workers, workers in other risk jobs and office workers
}

\author{
J.P. Zock*, M. Kogevinas*, J. Sunyer*, D. Jarvis ${ }^{\#}$, K. Torén ${ }^{\Uparrow}$, J.M. Antó*,+, for the European \\ Community Respiratory Health Survey
}

Asthma characteristics in cleaning workers, workers in other risk jobs and office workers. J.P. Zock, M. Kogevinas, J. Sunyer, D. Jarvis, K. Torén, J.M. Antó, for the European Community Respiratory Health Survey. (C)ERS Journals Ltd 2002.

ABSTRACT: Several studies have demonstrated an excess risk for asthma among cleaning workers. The aim of this analysis was to compare clinical, immunological and functional characteristics associated with asthma in cleaners and other occupational groups.

Cleaners, workers exposed to high molecular weight (MW) agents, workers exposed to low MW agents, and office workers were identified from an international communitybased epidemiological study. Influence of sex, smoking, age and atopy on the relationships with asthma was investigated. Rates of respiratory symptoms, bronchial hyperresponsiveness, atopic sensitisation and lung function were compared between asthmatics from the four groups (case-case analysis).

The risk for asthma in workers exposed to low MW agents was higher among nonatopics than among atopics. Case-case analysis showed no major differences in asthma characteristics between cleaners and workers exposed to high or low MW agents. Asthmatic cleaners had less atopy, more chronic bronchitis and a lower lung function as compared to office workers.

Asthma in cleaning workers showed many similarities with that in workers known to be at risk for occupational asthma. Atopic sensitisation did not seem to play an important role in cleaning-related asthma.

Eur Respir J 2002; 20: 679-685.

\begin{abstract}
*Respiratory and Environmental Health Research Unit, Institut Municipal d'Investigació Mèdica, Barcelona, Spain. ${ }^{\#}$ Dept of Public Health Sciences, King's College, London, UK. "Dept of Occupational and Environmental Medicine and Dept of Respiratory Medicine and Allergology, Sahlgrenska University Hospital, Göteborg, Sweden. ${ }^{+}$Dept of Experimental and Health Sciences, Universitat Pompeu Fabra, Barcelona, Spain.
\end{abstract}

Correspondence: J.P. Zock, Institut Municipal d'Investigació Mèdica (IMIM), Doctor Aiguader 80, E-08003 Barcelona, Spain.

Fax: 34932216448

E-mail: jpzock@imim.es

Keywords: Asthma, cleaning, European Community Respiratory Health Survey, occupation

Received: September 102001

Accepted after revision: April 102002

The European Commission supported the coordination of this work. Financial support was provided by the National Institute of Health, USA (NORA grant number 1R01HL62633-01).
Excess risk for asthma among cleaning workers has been reported in a number of general population studies [1-3]. An international analysis within the European Community Respiratory Health Survey (ECRHS) showed that an elevated risk for asthma among cleaners was present in most countries in this survey [1]. Cleaners are exposed to a variety of chemical agents [4, 5], and asthma surveillance studies have suggested that both work-aggravated asthma and new-onset occupational asthma cases could be related to cleaning products [6-8]. It has also been shown that the risk for asthma may vary between different locations where cleaning work is performed $[3,9]$. Case studies have revealed several agents that could be potentially responsible for cleaning-related asthma, such as chlorine and ammonia [8, 10], ethanolamines $[4,11]$, and quaternary ammonium compounds [12]. Finally, two different epidemiological analyses indicated that the use of sprays was associated with asthma among cleaners [9, 13].

It has been indicated that if cleaning exposures are associated with asthma, then cleaning work should be regarded as one of the most prevalent causes of occupational asthma [14]. There is still, however, limited knowledge on the determinants of the asthma risk in cleaners and the potential interactions with other factors, and there is only scarce information characterising the clinical features of asthma in cleaners. The aim of this study was to evaluate the characteristics of asthma risk and of the clinical picture of asthma among cleaning workers within the ECRHS, by comparing asthma-related characteristics in cleaners with those in three other occupational groups: workers exposed to high molecular weight (MW) agents, workers exposed to low MW agents, and office workers. 


\section{Methods}

\section{Study population}

The methodology for the ECRHS has been described elsewhere [15]. Participating centres selected an area, defined by pre-existing administrative boundaries, with a population of at least 150,000 . When possible, an appropriate local sampling frame was used to randomly select at least 1,500 males and 1,500 females, aged 20-44 yrs. In stage I, subjects were sent the ECRHS screening questionnaire asking about symptoms suggestive of asthma, the use of medication for asthma, and the presence of hay fever and nasal allergies. In stage II, which was conducted in 1990 1994 , a $20 \%$ random subsample of subjects who had completed the screening questionnaire and in most centres an additional subsample including subjects reporting current asthma symptoms and/or medication in the screening questionnaire ('symptomatic sample"), were invited to attend for a more detailed interview-led questionnaire, blood tests for the measurement of total and specific immunoglobulin (Ig)-E, spirometry and methacholine challenge.

In this analysis, 30 study centres with stage II questionnaire data were included $(\mathrm{n}=17,953)$. Centres were located both in Europe (Belgium, Germany, Iceland, Ireland, Italy, the Netherlands, Norway, Spain, Sweden, Switzerland, UK), and outside Europe (Australia, New Zealand and USA). From 1,328 subjects $(7 \%)$ no information on current or last held job was available, and for 119 additional subjects $(0.7 \%)$ information on age, smoking status or current asthma was missing.

The selection of subjects for the present analysis is shown in figure 1. Subjects were classified on the basis of their current or most recent job, which had been coded using the Office of Populations Censuses and Surveys (OPCS)-1980 classification [16]. Four occupational groups were identified: cleaners, workers exposed to high MW agents, workers exposed to low MW agents, and office workers.

Subjects with exclusively OPCS code 071-2 (including cleaners, window cleaners and chimney and road sweepers) were classified as cleaners. Those exposed to high MW agents were bakers and flour confectioners, and other food and tobacco-processing workers. The sensitisers involved in this occupational group induce asthma predominantly due to an $\operatorname{IgE}$ dependent mechanism. Those exposed to low MW agents were painters, hairdressers, and metal, wood, plastics and rubber workers. Most of these agents cause asthma through IgE-independent mechanisms [17]. Excluded from these two groups were workers who reported a previous job in cleaning.

Office workers were selected from professionals, clerical and administrative workers as described elsewhere [1]. In order to obtain an occupationally unexposed group, subjects working in jobs with exposure to biological dust, mineral dust, gases or fumes according to a job exposure matrix developed for the ECRHS [1] were excluded. Additionally, workers in other jobs with possible exposure to cleaning agents or other occupations with potentially

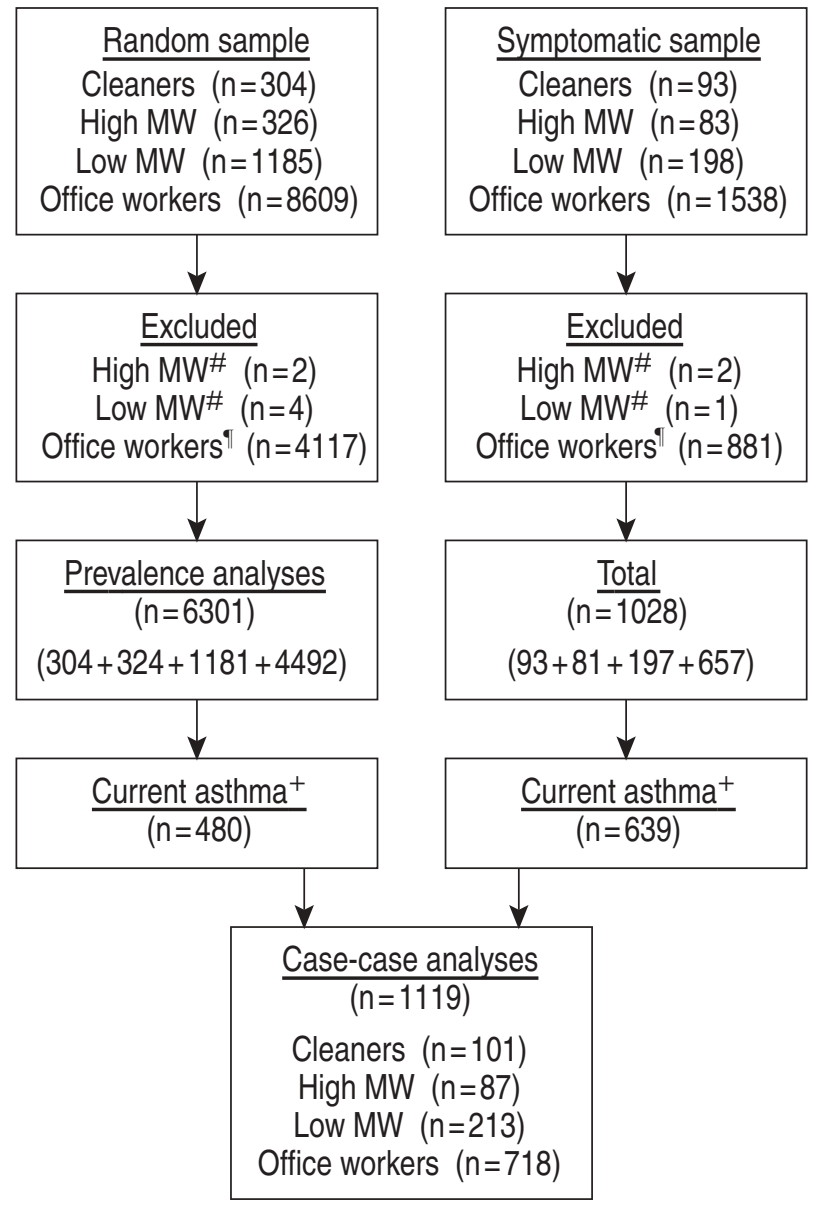

Fig. 1.-Stepwise overview of selection of subjects for analyses according to current or last held job. MW: molecular weight. \#: workers with a history in cleaning work; $\uparrow^{\text {: }}$ The following office workers were excluded: 1) workers with current exposure to biological dust, mineral dust, or gases/fumes according to a general job exposure matrix $(\mathrm{n}=1599+271)$, 2) workers with possible exposure to cleaning agents or other jobs with potentially asthma-related exposures $(n=432+116), 3)$ workers who had ever worked in a job with exposure to vapours, gas, dust or fumes $(n=2,048+467)$, or had ever changed or left their job because it affected their breathing $(n=38+27){ }^{+}$: attack of asthma in the past 12 months, and/or woken by an attack of shortness of breath.

asthma-related exposures (including medical radiographers, ophtalmic and dispensing opticians, chemical engineers, engineering technicians, technical engineers, restaurateurs, shelf fillers, domestic and school helpers, hospital ward orderlies, and care assistants) were excluded. Finally, subjects who reported that they had ever worked in a job with exposure to vapours, gas, dust or fumes, or who had changed or left a job because it affected their breathing, were also excluded from the group of office workers.

\section{Health outcome}

All 6,940 subjects $(6,301$ from the random sample and 639 from the symptomatic sample) attended an interviewer-led questionnaire on respiratory symptoms, medication, environmental and lifestyle factors, and smoking habits. In addition, the majority 
provided blood samples for serum IgE analyses $(\mathrm{n}=$ $5,100)$, and underwent baseline spirometry $(n=5,687)$ and a methacholine bronchial hyperresponsiveness test $(n=4,923)$.

As in previous analyses [1], asthma was defined as an attack of asthma in the past 12 months or having been woken by an attack of shortness of breath at any time in the last 12 months, or current use of asthma medication. Chronic bronchitis was defined as cough with phlegm on most days for as much as 3 months each year.

Subjects performed at least three acceptable reproducible lung function manoeuvres following standard spirometry procedures [18]. The following parameters were determined: forced expiratory volume in one second $(F E V 1)$, forced vital capacity (FVC) and peak expiratory flow (PEF); and the FEV1 to FVC ratio was calculated. Chronic obstructive pulmonary disease (COPD) was defined as both an FEV $1<80 \%$ of the sex-, age- and height-specific reference value [18, $19]$ and an $\mathrm{FEV} 1 / \mathrm{FVC}$ ratio $<0.7$.

Methacholine challenge was carried out using a dosimeter (Mefar, Brescia, Italy). Bronchial hyperresponsiveness was defined as a fall of at least $20 \%$ in FEV1 (PD20) associated with a methacholine dose of $\leqslant 1 \mathrm{mg}$.

Specific serum IgE against four common environmental aeroallergens (house dust mite, cat, Timothy grass and Cladosporium herbarum) was determined using the Pharmacia CAP System (Pharmacia Diagnostics, Uppsala, Sweden). Atopy was defined as a specific IgE level $>0.35 \mathrm{kU} \cdot \mathrm{L}^{-1}$ to at least one out of the four allergens, previously suggested to be a sensitive definition of atopy [20].

\section{Statistical analysis}

Two different analyses were performed. First, the risk of asthma for cleaners, for high MW exposed workers, and for low MW exposed workers was evaluated using the group of office workers as a reference category. For this analysis, 6,301 subjects of the random sample were included (fig. 1). Odds ratios (ORs) with 95\% confidence intervals adjusted for sex, age category, current smoking and study centre were calculated using unconditional logistic regression analyses. These analyses were performed after stratification by sex, age group, current smoking, and atopy. Differences in ORs between the strata were evaluated using multiplicative interaction terms.

Second, case-case analyses were performed. This type of analysis is typically performed to compare the exposure status of a group of cases with the disease under study with another group of cases with a different disorder or a phenotypical or genotypical variant [21, 22]. This design was used to compare clinical, immunological and functional characteristics of groups of cases with asthma (defined as above) with a different exposure status. Asthma-related characteristics were compared between cleaners, high MW exposed workers, low MW exposed workers, and office workers. For this analysis asthmatic subjects from the random sample and the symptomatic sample were joined $(n=1,119)$. ORs of asthma-related characteristics for occupational groups relative to office workers were calculated using logistic regression analyses as described earlier. Finally, lung function indices were compared between the four groups of asthmatics using linear regression analyses adjusting for sex, age, height, smoking and study centre.

\section{Results}

The group of cleaners consisted of more females as compared to the other occupational groups (table 1). Workers exposed to low MW agents were predominantly males. Current smoking was more common among groups of exposed workers as compared to office workers. The prevalence of asthma and bronchial hyperresponsiveness was higher for cleaners, while the prevalence of atopy was lower than for the other groups. The prevalence of chronic bronchitis was higher for all three groups of exposed workers as compared to office workers.

Table 1.-General and respiratory health characteristics of the study population (random sample) by occupational group

\begin{tabular}{|c|c|c|c|c|}
\hline & Office & Cleaning & High MW & Low MW \\
\hline Total & 4492 & 304 & 324 & 1181 \\
\hline Females & $3008(67.0)$ & $254(83.6)$ & $164(50.6)$ & $180(15.2)$ \\
\hline Age $\geqslant 35$ yrs & 2152 (47.9) & $155(51.0)$ & $125(38.6)$ & $502(42.5)$ \\
\hline Current smokers & $1451(32.3)$ & $151(49.7)$ & $152(46.9)$ & $536(45.4)$ \\
\hline Current asthma & $308(6.9)$ & $43(14.1)$ & $35(10.8)$ & $94(8.0)$ \\
\hline Chronic bronchitis & $107(2.4)$ & $20(6.6)$ & $25(7.7)$ & $60(5.1)$ \\
\hline Bronchial hyperresponsiveness $^{+}$ & $449(13.7)$ & $42(24.3)$ & $35(15.0)$ & $107(11.9)$ \\
\hline $\mathrm{COPD}^{\S}$ & $61(1.6)$ & $8(3.6)$ & $11(4.0)$ & $27(2.7)$ \\
\hline Atopy $^{f}$ & $1097(33.3)$ & $55(26.7)$ & $81(32.8)$ & $314(34.5)$ \\
\hline
\end{tabular}

Data are presented as $\mathrm{n}(\%)$ unless otherwise stated. MW: molecular weight; COPD: chronic obstructive pulmonary disease. ": attack of asthma in the past 12 months, and/or woken by an attack of shortness of breath in the last 12 months, and/or current use of asthma medication; ${ }^{\uparrow}$ : productive cough on most days for at least 3 months each year. Missing data for 11 subjects; ${ }^{+}$: a fall of at least $20 \%$ in forced expiratory volume in one second (FEV1) associated with a methacholine dose of $\leqslant 1 \mathrm{mg}, \mathrm{n}=3283,173,233$, and 897 , respectively; ${ }^{\text {. }}$ FEV1 $<80 \%$ pred and $\mathrm{FEV} 1 /$ forced vital capacity ratio $<0.7$, $\mathrm{n}=3729,224,274$, and 1003, respectively; ${ }^{f}$ : specific immunoglobulin $\mathrm{E}$ to common allergens, $\mathrm{n}=3292,206,247$, and 910 , respectively. 
Table 2.-Risk for current asthma ${ }^{\#}$ relative to office workers: random population sample of 30 study centres of the European Community Respiratory Health Survey

\begin{tabular}{lccc}
\hline & Cleaning & High MW & Low MW \\
\hline All & $2.47(1.7-3.6)$ & $1.81(1.2-2.7)$ & $1.36(1.0-1.8)$ \\
Females & $2.53(1.7-3.8)$ & $1.45(0.8-2.5)$ & $1.16(0.7-2.0)$ \\
Males & $2.19(0.9-5.5)$ & $2.37(1.3-4.2)$ & $1.51(1.1-2.1)$ \\
Age 20- & & & \\
$\quad$ 34 yrs & $1.81(1.0-3.3)$ & $1.35(0.8-2.3)$ & $1.26(0.9-1.8)$ \\
Age 35- & & & \\
$\quad$ 44 yrs & $3.42(2.1-5.6)$ & $2.68(1.5-4.8)$ & $1.47(1.0-2.3)$ \\
$\begin{array}{l}\text { Nonsmokers } \\
\text { Current }\end{array}$ & $2.28(1.4-3.8)$ & $1.64(1.0-2.8)$ & $1.36(1.0-1.9)$ \\
$\quad$ smokers & $2.72(1.6-4.7)$ & $1.88(1.0-3.5)$ & $1.41(0.9-2.2)$ \\
$\begin{array}{l}\text { Nonatopics } \\
\text { Atopics }\end{array}$ & $3.62(2.1-6.3)$ & $1.53(0.8-3.1)$ & $2.06(1.3-3.2)$ \\
\hline
\end{tabular}

Data are presented as odds ratios (OR) $(95 \%$ confidence interval), adjusted for sex, age category, current smoking and study centre. In stratified analyses, ORs were adjusted for the other listed host factors in the table, minus the stratifying factor and atopy. See table 1 for $\mathrm{n}$ numbers. MW: molecular weight. \#: attack of asthma in the past 12 months, and/or woken by an attack of shortness of breath in the last 12 months, and/or current use of asthma medication. *: $\mathrm{p}<0.05$ for multiplicative interaction.

The risk for asthma in the three exposed groups was fairly similar for males and females, and for smokers and nonsmokers (table 2). Older cleaning workers and older workers exposed to high MW agents tended to have a higher risk, but the interaction with age was not statistically significant. Workers exposed to low MW agents, who showed no evidence of atopy, were at a significantly higher risk of having asthma than those who were atopic (interaction $\mathrm{p}=0.01$ ). The same trend was found for cleaning workers, but the interaction was not statistically significant. After additional adjustment for level of education, the ORs shown in table 2 decreased by 3 to $8 \%$ (results not shown). This indicated that socioeconomic status did not act as a strong confounding variable within the associations under study.
Approximately one-half of the asthmatics had ever been diagnosed with asthma by a physician, being similar for all occupational groups (table 3). Approximately $30 \%$ of the subjects who reported ever having asthma, had their first attack of asthma at age $\geqslant 15$ yrs. Bronchial hyperresponsiveness tended to be higher in cleaners, but the difference with office workers was not statistically significant. All exposed groups suffered from tight or wheezy chest at work more often than office workers. Cleaners and high MW exposed workers had more chronic bronchitis than office workers. Chronic airflow limitation occurred more frequently among high MW exposed workers. Atopy was less prevalent for cleaners and workers exposed to low MW agents. The prevalence of atopy for high MW exposed asthmatics was similar to that of office workers.

Lung function in both cleaners and workers exposed to high MW agents with asthma tended to be lower than in office workers with asthma (table 4), being statistically significant for the PEF. For low MW exposed workers, lung function was not different from that for office workers.

Table 4.-Case-case analyses among subjects with current asthma: lung function indices in selected occupational groups

\begin{tabular}{lcccc}
\hline & Office $^{\#}$ & Cleaning & High MW & Low MW \\
\hline Subjects $\mathrm{n}$ & 543 & 82 & 63 & 179 \\
FEV1 mL & 3352 & $-97(72)$ & $-151(83)$ & $+37(60)$ \\
FVC mL & 4242 & $-50(75)$ & $-144(86)$ & $-13(62)$ \\
FEV $1 /$ FVC $\%$ & 79.3 & $-1.44(1.12)$ & $-1.77(1.27)$ & $+0.67(0.90)$ \\
PEF L $\cdot \mathrm{s}^{-1+}$ & 7.56 & $-0.57(0.19)^{*}$ & $-0.63(0.22)^{*}$ & $-0.04(0.16)$ \\
\hline
\end{tabular}

Data are presented as mean difference between occupational group and office workers (SEM) unless otherwise stated. MW: molecular weight; FEV1: forced expiratory volume in one second; FVC: forced vital capacity; PEF: peak expiratory flow. \#: mean value standardised for sex, age and height; ": values adjusted for sex, age, height, smoking status and study centre; ${ }^{+}$: missing data for three subjects. $*: \mathrm{p}<0.05$.

Table 3. - Case-case analyses among subjects with current asthma: clinical and immunological characteristics in selected occupational groups, with adjusted odds ratios (OR) relative to office workers

\begin{tabular}{|c|c|c|c|c|c|c|c|}
\hline & \multirow{2}{*}{$\begin{array}{c}\text { Office } \\
\text { Prevalence \% }\end{array}$} & \multicolumn{2}{|c|}{ Cleaning } & \multicolumn{2}{|c|}{ High MW } & \multicolumn{2}{|c|}{ Low MW } \\
\hline & & Prevalence $\%$ & $\mathrm{OR}^{\#}$ & Prevalence $\%$ & $\mathrm{OR}^{\#}$ & Prevalence \% & $\mathrm{OR}^{\#}$ \\
\hline Subjects $n$ & 718 & 101 & & 87 & & 213 & \\
\hline Physician diagnosed asthma & 57.5 & 45.5 & 0.84 & 49.4 & 0.79 & 50.0 & 0.92 \\
\hline Adult onset asthma & 28.0 & 33.7 & 1.53 & 25.3 & 1.22 & 22.1 & 1.27 \\
\hline Bronchial hyperresponsiveness $^{+}$ & 46.4 & 57.1 & 1.60 & 45.2 & 1.00 & 39.7 & 1.01 \\
\hline Chest tight/wheezy at work & 26.3 & 48.4 & $2.71 *$ & 47.6 & $3.11 *$ & 45.5 & $3.25^{*}$ \\
\hline Chronic bronchitis & 9.1 & 20.8 & $2.14 *$ & 19.5 & $2.19^{*}$ & 15.6 & 1.22 \\
\hline $\mathrm{COPD}^{\S}$ & 9.4 & 7.3 & 1.28 & 20.6 & $2.73 *$ & 9.5 & 0.82 \\
\hline Atopy $^{f}$ & 60.9 & 38.3 & $0.51 *$ & 57.8 & 0.87 & 45.3 & $0.38^{*}$ \\
\hline
\end{tabular}

MW: molecular weight. " : OR relative to office workers, adjusted for sex, age category, current smoking and study centre; I: first asthma attack at age 15 or onwards; ${ }^{+}$: a fall of at least $20 \%$ in forced expiratory volume in one second (FEV1) associated with a methacholine dose of $\leqslant 1 \mathrm{mg}, \mathrm{n}=422+56+42+141 ;{ }^{\S}$ : FEV $1<80 \%$ pred and FEV $1 /$ forced vital capacity ratio $<0.7, \mathrm{n}=543+82+63+179 ;{ }^{f}$ : specific immunoglobulin $\mathrm{E}$ to common allergens, $\mathrm{n}=507+81+64+161 .{ }^{*}: \mathrm{p}<0.05$. 


\section{Discussion}

In this study no major differences in clinical, immunological or functional characteristics of asthma between cleaners and workers known to be at risk for occupational asthma could be observed. Cleaningrelated asthma was accompanied by less atopy, more symptoms of bronchitis and a lower lung function, as compared to nonoccupational asthma. Asthma in cleaning workers seemed to have similarities with that in workers exposed to low MW agents, as well as with workers exposed to high MW agents.

No major modification of the cleaning-related effect on asthma was found for sex, age, or smoking. Only a potential negative interaction of cleaning exposures with atopy was found. This pattern was also observed for workers exposed to low MW agents, but not for workers with high MW exposures. This finding is in agreement with the fact that atopic individuals are at increased risk for asthma due to some occupational agents that induce specific $\operatorname{IgE}$ antibodies [23]. For (low MW) agents that do not induce specific IgE, the effect modification by atopy is less clear. Interestingly, a surveillance study on work-related asthma predominantly due to unknown asthma inducers in the USA showed that new-onset work-related asthma cases were less likely to have a history of allergies than cases of work-aggravated asthma [6]. The case-case analysis in the present study confirmed that asthmatics performing cleaning work or exposed to low MW agents, had less atopy as compared to individuals with nonoccupational asthma. The prevalence of atopy for asthmatics exposed to high MW agents, however, was similar to that for nonexposed patients. These findings suggest that it is unlikely that IgEdependent mechanisms have a predominant role in cleaning-related asthma.

In this study, it was found that asthma in cleaning workers was accompanied by symptoms of productive cough, pointing towards chronic bronchitis, in a higher proportion than in office workers. This finding agrees with an epidemiological study among female Danish cleaners where asthma was a strong risk factor for the development of bronchitis symptoms [13]. The present authors speculate that regular exposure to irritants in cleaning work may lead to mucus hypersecretion and to chronic productive cough, often referred to as industrial bronchitis [24]. Although evidence for an elevated prevalence of fixed airflow limitation among cleaners with asthma could not be demonstrated, spirometric indices for this group tended to be lower as compared to asthmatics without occupational exposures. Interestingly, asthmatics exposed to high MW agents also had a lower lung function than asthmatics employed in office work. On the contrary, lung function in asthmatics exposed to low MW agents was similar to that in asthmatic office workers. It can be speculated that occupational asthma with type I immunological mechanisms is characterised by a different pathophysiological variant than occupational asthma with other immunological mechanisms. It is also possible that due to concomitant irritant exposures, comorbidity of chronic bronchitis is more prevalent among high MW exposed than among low MW exposed workers, resulting in a steeper lung function decline.

The assessment of occupational exposures in this study was performed on the basis of occupational code only, resulting in crude estimates. Inherent to the used coding system, cleaners, window cleaners and chimney and road sweepers were grouped together. It can be expected that chimney and road sweepers have different exposures than other (indoor) cleaners. A more detailed follow-up interview among 68 of the 91 Spanish cleaners forming part of the present analysis [9] showed that 67 out of these 68 were indoor cleaners, and one was a road sweeper. Although this figure may be different in other countries within this analysis, it is assumed that the vast majority of 'cleaners' in this analysis performed more or less similar cleaning tasks in buildings.

It is possible that cleaners more often reported respiratory complaints associated with odours of the cleaning products they use $[25,26]$ leading to a recallbias. Indeed, approximately one-half of the asthmatic cleaners indicated work-related asthmatic symptoms, but this was the same in other exposed workers. Moreover, the present analyses showed that approximately one-half of the cleaners with asthmatic symptoms were ever diagnosed as having asthma, which was comparable with nonexposed asthmatics. Thus, recall bias probably did not play a major role in this study.

The present study was not able to assess the role of specific characteristics of the cleaning job. It would have been interesting to know differences between the location of cleaning work, cleaning activities and used products. A Spanish analysis within the ECRHS suggested that the excess risk for asthma was predominantly attributable to domestic cleaning [9]. A Finnish study showed that asthma incidence was highest among cleaners employed in the manufacture of basic metals and food products [3].

Cleaners were compared with workers exposed to high MW agents, and other workers exposed to low MW agents. In many settings, cleaners are probably exposed to a mixture of high MW agents, low MW agents, and irritants [4, 5]. However, comparing cleaners with a group with undefined mixed occupational exposures would have been difficult to interpret. Another limitation of this study was that year of asthma onset and start of the cleaning job could not be compared. This would have enabled a more specific analysis of work-related asthma.

In conclusion, asthma in cleaning workers showed many similarities with asthma in jobs known to be at risk for occupational asthma. Atopy did not seem to play an important role in cleaning-related asthma, which has also been observed for workers exposed to low molecular weight agents. Cleaning workers with asthma showed an excess prevalence of chronic bronchitis. A follow-up of this population is currently underway and will help evaluate specific risk factors for asthma in this workforce of cleaners. Further studies should focus on the identification of (chemical) exposures including irritants, specific sensitisation to cleaning agents, and clinical diagnosis of cases. 
Acknowledgements. Co-ordination of the ECRHS: Dept of Public Health Sciences, King's College, London, UK: P. Burney, S. Chinn, C. Luczynska, D. Jarvis, E. Lai, J. Potts.

Participating centres providing occupational information: Australia: M. Abramson, J. Kutin (Melbourne); Belgium: P. Vermeire, F. van Bastelaer (Antwerp South, Antwerp Central); Germany: H. Magnussen, D. Nowak (Hamburg); H.E. Wichmann, J. Heinrich (Erfurt); Iceland: T. Gislason D. Gislason (Reykjavik); Ireland: J. Prichard, S. Allwright, D. MacLeod (Dublin); Italy: M. Bugiani, C. Bucca, C. Romano (Turin), R. de Marco lo Cascio, C. Campello (Verona), A. Marinoni, I. Cerveri, L. Casali, L. Perfetti (Pavia); The Netherlands: B. Rijcken, J.P. Schouten, M. Kerkhof, H.M. Boezen (Groningen, Bergen op Zoom, Geleen); New Zealand: J. Crane, S. Lewis, N. Pearce (Wellington, Christchurch, Hawkes Bay); Norway: A. Gulsvik, E. Omenaas (Bergen); Spain: J.M. Antó, J. Sunyer, J. Soriano, M. Kogevinas, A. Tobías, J. Roca (Barcelona), N. Muniozguren, J. Ramos González, A. Capelastegui (Galdakao), J. Martínez-Moratalla,

E. Almar (Albacete) J. Maldonado Pérez,

A. Pereira, J. Sánchez (Huelva), J. Quirós,

I. Huerta (Oviedo); Sweden: G. Boman, C. Janson, E. Björnsson (Uppsala), L. Rosenhall, E. Norrman B. Lundbäck (Umea), N. Lindholm, P. Plaschke, K. Torén (Göteborg); Switzerland: N. Künzli (Basel); United Kingdom R. Hall (Ipswich), B. Harrison (Norwich), J. Stark (Cambridge); USA: S. Buist, W. Vollmer, M. Osborne (Portland).

The following grants helped to fund the local studies: Australia: Allen and Hanbury's. Belgium: Belgian Science Policy Office, National Fund for Scientific Research. Germany: GSF, and the Bundesminister für Forschung und Technologie, Bonn. Italy: Ministero dell'Universita e della Ricerca Scientifica e Tecnologica, CNR, Regione Veneto grant RSF n. 381/05.93. The Netherlands: Ministry of Welfare, Public Health and Culture. New Zealand: Asthma Foundation of New Zealand, Lotteries Grant Board, Health Research Council of New Zealand. Norway: Norwegian Research Council project no. 101422/310. Spain: Ministerio Sanidad y Consumo FIS grants \#91/0016060/00E-05E., \#92/0319, \#93/0393, CIRIT 1999SGR00241, Hospital General de Albacete, Hospital General Juan Ramón Jiménez, Consejeria de Sanidad Principado de Asturias. Sweden: The Swedish Medical Research Council, the Swedish Heart Lung Foundation, the Swedish Association against Asthma and Allergy. Switzerland: Swiss National Science Foundation grant 402628099. United Kingdom: National Asthma Campaign, British Lung Foundation, Department of Health, South Thames Regional Health Authority. USA: United States Department of Health, Education and Welfare Public Health Service Grant \#2 S07 RR05521-28.

The job exposure matrix was developed by H. Kromhout and R. Vermeulen (University of Utrecht, the Netherlands). The contribution of M. Lew (Jagiellonian University of Kraków, Poland) is gratefully acknowledged.

\section{References}

1. Kogevinas M, Antó JM, Sunyer J, et al. A population based study on occupational asthma in Europe and other industrialised countries. Lancet 1999; 353: 1750 1754.

2. Ng TP, Hong CY, Goh LG, Wong ML, Koh KT, Ling SL. Risks of asthma associated with occupations in a community-based case-control study. Am $J$ Ind Med 1994; 25: 709-718.

3. Karjalainen A, Martikainen R, Karjalainen J, Klaukka T, Kurppa K. Excess incidence of asthma among Finnish cleaners employed in different industries. Eur Respir J 2002; 19: 90-95.

4. Wolkoff P, Schneider T, Kildeso J, Degerth R, Jaroszewski M, Schunk H. Risk in cleaning: Chemical and physical exposure. Sci Total Environ 1998; 215: 135-156.

5. Børglum B, Hansen AM. Kortlægning af vaske- og rengøringsmidler. (A survey of washing and cleaning agents). AMI report nr. 44, 1994. Copenhagen, Arbejdsmiljøinstitutet, 1994.

6. Reinisch F, Harrison RJ, Cussler S, et al. Physician reports of work-related asthma in California, 1993-1996. Am J Ind Med 2001; 39: 72-83.

7. Romero Jajosky AR, Harrison R, Reinisch F, et al. Surveillance of work-related asthma in selected U.S. states using surveillance guidelines for state health departments - California, Massachusetts, Michigan, and New Jersey, 1993-1995. MMWR Surveillance Summaries. $M M W R$ 1999; 48: 1-20.

8. Meredith S. Reported incidence of occupational asthma in the United Kingdom, 1989-90. J Epidemiol Community Health 1993; 47: 459-463.

9. Zock JP, Kogevinas M, Sunyer J, et al. Asthma risk, cleaning activities and use of specific cleaning products in Spanish indoor cleaners. Scand J Work Environ Health 2001; 27: 76-81.

10. Quirce S, Gala G, Pérez-Camo I, Sánchez-Fernández C, Pacheco A, Losada E. Irritant-induced asthma: Clinical and functional aspects. J Asthma 2000; 37: 267-274.

11. Savonius B, Keskinen H, Tuppurainen M, Kanerva L. Occupational asthma caused by ethanolamines. Allergy 1994; 49: 877-881.

12. Burge PS, Richardson MN. Occupational asthma due to indirect exposure to lauryl dimethyl benzyl ammonium chloride used in a floor cleaner. Thorax 1994; 49 : 842-843.

13. Nielsen J, Bach E. Work-related eye symptoms and respiratory symptoms in female cleaners. Occup Med 1999; 49: 291-297.

14. Burge S. Occupation and lung disease. Scand J Work Environ Health 2000; 26: 369-371.

15. Burney PGJ, Luczynska C, Chinn S, Jarvis D. The European Community Respiratory Health Survey. Eur Respir J 1994; 7: 954-960.

16. Office of Populations Censuses and Surveys. Classification of Occupations 1980 (OPCS-CO). London, HMSO, 1980.

17. Van Kampen V, Merget R, Baur X. Occupational airway sensitizers: An overview on the respective literature. Am J Ind Med 2000; 38: 164-218.

18. Roca J, Burgos F, Sunyer J, et al. Reference values for forced spirometry. Eur Respir J 1998; 11: 1354-1362.

19. Roca J, Sanchis J, Agustí-Vidal A, et al. Spirometric 
reference values for a meditterranean population. Bull Eur Physiopathol Respir 1986; 22: 217-224.

20. Burney P, Malmberg E, Chinn S, et al. The distribution of total and specific serum IgE in the European Community Respiratory Health Survey. J Allerg Clin Immunol 1997; 99: 314-322.

21. McCarthy N, Giesecke J. Case-case comparisons to study causation of common infectious diseases. Int J Epidemiol 1999; 28: 764-768.

22. Porta M, Malats N, Jariod M, et al. Real FX, for the PANKRAS II Study Group. Serum concentrations of organochlorine compounds and K-ras mutations in exocrine pancreatic cancer. Lancet 1999; 354: 2125 2129.
23. Venables KM, Chang-Yeung M. Occupational Asthma. Lancet 1997; 349: 1465-1469.

24. Hendrick DJ. Occupation and chronic obstructive pulmonary disease (COPD). Thorax 1996; 51: 947-955.

25. Baldwin CM, Bell IR, $\mathrm{O}^{\prime}$ Rourke MK. Odor sensitivity and respiratory complaint profiles in a communitybased sample with asthma, hay fever, and chemical odor intolerance. Toxicol Ind Health 1999; 15: 403409.

26. Van den Bergh O, Stegen K, Van Diest I, et al. Acquisition and extinction of somatic symptoms in response to odours: a Pavlovian paradigm relevant to multiple chemical sensitivity. Occup Environ Med 1999; 56: 295-301. 